\title{
METADISCOURSE, WRITER IDENTITY AND READER CONSTRUCTION AMONG NOVICE ARABIC-SPEAKING ESL WRITERS
}

\author{
Christina A. DeCoursey \\ Silk Road International University, Samarkand, Uzbekistan
}

\begin{abstract}
This study used qualitative analyses to explore novice ESL writers' concepts of writers, readers and texts. Metadiscourse studies tabulate frequencies of discourse markers in order to characterise the different ways novices and experts, native-speakers and non-native speakers, construct themselves as writers, engage with their readers, and guide readers through their text. But the picture created by these descriptive statistics lacks many content areas voiced by student writers, including their reliance on visual content, and their emotions. Student writers' experiences in a world saturated by visual media and marketing views are also factors shaping how they construct their identities as writers, the identities of their projected readers, and how they understand what they are doing when writing text. This study used content and transitivity analyses to assess how Arabic native-speaker novices understand themselves as writers, how they project their readers' identities, and how they try to engage them. Results show that visuals are indistinct from text, and verbs of seeing are used for reader understanding, in novice writers' sense of their texts, and how they understand engaging the reader. These novices have a demographically granular assessment of audiences, but aim to please readers with expected content rather than challenge them with academic content, and they downplay important elements of teacher talk, syllabus and secondlanguage (L2) composition instruction, particularly data, research, structure and language.
\end{abstract}

Keywords: metadiscourse, systemic functional linguistics, content analysis, transitivity analysis, English for Academic Purposes, writer concepts, reader concepts

\section{Article history:}

Received: 2 November 2019;

Reviewed: 22 November 2019;

Accepted: 20 December 2019;

Published: 30 December 2019

Copyright (c) 2019 Christina A. DeCoursey

This open access article is published and distributed under a CC BY-NC 4.0 International License which permits non-commercial use, distribution, and reproduction in any medium, provided the original author and source are credited. Permissions beyond the scope of this license may be available at cadsilkroad@gmail.com. If you want to use the work commercially, you must first get the authors' permission.

Citation: DeCoursey, C. A. (2019). Metadiscourse, Writer Identity and Reader Construction among Novice Arabic-Speaking ESL Writers. English Studies at NBU, 5(2), 284-307.

https://doi.org/10.33919/esnbu.19.2.6

Professor DeCoursey received her PhD from the University of Toronto. She founded and ran the MA in English Language Arts at the Hong Kong Polytechnic University. She was Chair of the American University in Science and Technology's Department of Language, Literature and Translation in Beirut, the TESOL ESP rep for the Middle East, and Division Head of Humanities at Innopolis University in Kazan, Russia. Her research interests include Appraisal analysis and healthcare communication. 
Instructors of university composition classes routinely assess student essays in terms of their content and their structure, using terminology such as "thesis statement", "topic sentence”, "argument", "cohesion" and others. They discuss the language students use when writing essays, using terms such as "grammar" and "register", and the mechanics of student essays using terms such as "punctuation", "spelling" and "citation" (Alexander, 2012; Biber \& Gray, 2010). This teacher-talk is felt to shape how learners understand the kind of thing academic writing is, and the metalanguage they employ when talking about their own essays (Gilquin \& Paquot, 2008). L2 writers often take in lexical bundles from their teachers, redeploying them in their own work (Meunier \& Granger, 2008). However, L2 writers also have their own, personal lives, and this also shapes what they think they are doing, when they write. However, academic analysis has rarely explored how student writers' own lives shape their understanding of their rhetoric practice.

\section{Literature Review}

The term metadiscourse refers to the language used by writers to construct their own manifestation within the text, and the language through which they communicate to readers about their meaning. Two models of metadiscourse have been articulated, including the reflexive model focused on elements that organise the text, (Ädel \& Mauranen, 2010), and the integrative model which embraces a greater range of interpersonal resources writers employ, and includes how writers construe readers and texts (Hyland, 2005). The integrative model has given rise to two analytic approaches. Interactive analyses focus on resources through which writers limit and direct how readers understand their text. These studies tabulate frequencies of transitions (but, thus), frame markers (in conclusion, finally), endophoric markers (as noted blow, see section X) and code glosses (such as, namely). Interactional analyses focus on resources through which writers implant themselves within the text, and create relationships with their material and their readers. These studies tabulate frequencies of hedges (perhaps, somewhat), boosters (clearly, in fact), engagement markers (you can see that, note that) and self-mentions (first-person pronouns). Quantitative studies have tended to tabulate frequencies, where studies using qualitative methods have analysed extended examples in order to highlight the complexity of the writer's relationships with text and reader (Hyland \& Tse, 2004). While these studies have improved our understanding of inexpert 
academic writers' text, they cannot reveal how those inexpert writers understand what they are doing, when they make those choices in their writing.

Metadiscourse studies began by addressing corpora formed from expert academic writing, at the level of masters, PhD and research article writing (Hyland, 2002; 2004). More recently they have focused on novice and L2 writers, as the teaching of English for Academic Purposes (EAP) has become a global activity (Negretti \& Kuteeva, 2011). Hyland's (2006) study comparing how Hong Kong final-year undergraduates and expert academic writers constructed relationships with their readers found that expert writers used interpersonal devices more than twice as often as novices. He asserted that “[a]nticipating readers' expectations and responses to what they write...can be very difficult for novices who are not used to seeing writing as interactive or to imagining the perceptions, interests, and requirements of a potential audience" (Hyland 2006, 364). He concluded that Hong Kong novices were reluctant to engage the reader, viewing academic writing as quite strictly referential. He also argued for the influence of the field, stemming from the relative inability of soft-knowledge fields such as humanities and the social sciences to make unequivocal knowledge claims, meaning that these writers were more likely to use persuasive interpersonal devices such as second person pronouns than were writers in the sciences. Thus he suggested a cline between invitational devices which invite writer-reader solidarity and establish greater intimacy, such as second-person pronouns and asides, at one end, and manipulative devices such as directives and questions which manoeuvre the reader in certain directions, at the other.

However, a separate stream of research on Confucian learning styles suggested these could be accounted for as dimensions of Chinese culture such as valuing accuracy over emotional immediacy (Cheng, 2000). Solidarity is pre-eminently important in Chinese culture, but is assumed and explicitly not articulated (Yao, 2000), something non-Asians often encounter when seeking to understand why Chinese people do not say thank-you to each other (Al Falasi, 2007). Chinese culture discourages the expression of personal views and emotion (Chen et al 2005). Culturally polite styles in Chinese culture are indirect, employing hedges, and mixing positive and negative comments (Wei \& Lei, 2011). These conventions must impact Chinese native-speakers' writing style, and in particular the use of interpersonal and engagement resources. We should expect that 
other novice writers' cultures would impact them also. But cultural values are difficult to use, in analysing metadiscourse (Søndergaard, 2012).

Culture is a factor in several recent metadiscourse studies (Abdi, 2009; PérezLlantada, 2010; Mur-Dueñas, 2011). Vande Kopple (2012) explored multiple examples of how culturally specific writing conventions shaped novice writers' use of interpersonal resources in constructing readers and texts. Exploring the semantic impact of non-native speaker constructions in English, he asserts that "metadiscourse deserves a prominent place in second-language instruction" in helping students understand English-language conventions for accuracy, ethics and forms of address (Vande Kopple, 2012, 42). This perspective fits with research in contrastive rhetoric, exploring the cultural sources of stylistic and ethical contentions in academic writing, within different languages and varieties (Connor, Nagelhout \& Rozycki, 2008).

The culture of contemporary novice L2 writers is complex. To begin with, it goes well beyond the local. As English learners, they participate in $\mathrm{n}$ imagined global culture with nearly 2 billion others worldwide (Graddol, 2007). Globalisation has redefined their identities, allowing them to participate in selected transnational trends, and to blend local with international elements of their choice (Doiz, Lasagabaster, \& Sierra, 2011). This study explores how Arabic native-speakers of English as a second-language (ESL) employ metadiscourse to write about themselves as writers, their texts, and their readers. Some impacts of Arabic-speakers' cultural on their use of metadiscourse have already been studied. Sultan's (2011) study of metadiscourse differences between Arabic and English native speaker research writers showed that Arabic-speaker writers used more interactive discourse markers, particularly using transitions three times as frequently as English speakers, as well as using evidentials and code glosses more frequently. By comparison, they used fewer frame markers and endophoric markers. Alshahrani's (2015) study of Arabic native-speaker academic writers suggests that the relative usage of specific discourse markers reflects Arabic writers' field of study and institutional context. However, there are no studies of more the impacts of contemporary, transnational cultural elements, on the metadiscourse of Arabic speakers. The present study examines the views of Arabic-speaker ESL novice writers. These novice writers naturally reflect the $21^{\text {st }}$ century context, of ubiquitous crossplatform computing and social networking (Crystal, 2006). The tools, platforms and 
domains of their daily digital literacies inform how they write (Mangan, 2008). The authentic composing habits they have grown up with inform their understanding of themselves as communicators, of the texts they write, and of how to engage with their readers (Fitze, 2006). Thus, we should expect that metadiscourse will be reframed by contemporary digital discourse.

Conventional metadiscourse research seems relatively unable to frame these cultural and digital elements of novice writers' identities, and their understanding of their rhetorical practice. While it has allowed researchers to say quite precisely what various groups of writers are doing, it is less successful in revealing why they do so, and what it means to them. For this, the rich content of a qualitative study would be more useful. This study aims to question the connotations of the term novice, which may include a sense of uncertainty in the role of the writer, or diffidence in forming relationships with readers. This paper suggests that this is simply not the case, and that contemporary L2 novice writers would be better understood as assertively selfconfident in their understanding of their role and their relationship to their readers. This is not to argue that their views are sufficiently developed or accurate. However, this paper does attempt to problematise the term 'novice'. Hyland asks, "Should students be writing for their teachers, their peers or their examiners?" (2012, p. 364). While expert writers understand the academic rhetorical situation and novices cannot, contemporary novices appear to have written the teacher out of the picture, and placed their peers squarely in the position of dominance. EAP instructors may or may not agree with those ideas. Yet we must acknowledge that EAP has been transformed from the bottom up, in areas such as World Englishers, active pedagogies, gender and identity issues, evolving teacher and student roles, and others. Metadiscourse, then, is interdiscursive. Metadiscourse is a two-way street.

This study explores Arabic native-speaker novice views of themselves as writers, their texts and readers. It elicited extensive qualitative data from novice writers, in order to create a complex picture of their self-understanding. This was then used to reflect on the current understandings coming from conventional metadiscourse studies. Research questions included the following: what content do Arabic native-speaker novice writers realise, about themselves as writers? When engaging readers and 
shaping their texts? What kinds of readers do they project? How do they understand their agency as writers? The agency of the text, and of readers?

\section{Method}

Qualitative data was collected from 85 participants, all of whom were Arabic native-speakers, and students at a US-accredited, English-medium-of-instruction university in Cairo, Egypt. All had advanced English proficiency, having attained the IELTS 5.5 or TOEFL iBT46-59 level required for institutional admission. All were registered in a section of a freshman composition course. While information on participant majors was not available, all sections contained a variety of majors. Within the institution, there were more than three times as many undergraduate science, engineering and business than social science and humanities majors (AUC, 2015). Participants were invited to write a weekly personal reflection of about 100 words on the topic, "What was this class like for you this week, and why?" The prompt was framed as a generalised, open stimulus, to reduce artificially defining and structuring thematic content in the data as would be the case if a survey had been used. Instead, this method allowed participants to realise content they felt was important to them (Neumann, 2013). Given the nature of teacher talk and of the assignments in composition courses, writers, texts and readers were bound to be realised as topics, and could be extracted analytically. Data was collected weekly over four consecutive weeks, during which time participants produced their final research essay. Participants had previously produced two essays, both of which had been through three drafts. Therefore, they had sufficient experience to understand the composition terminology that would be realised in the classroom. They also had a personal experience of producing a university research essay. However, their experience was not sufficient to allow them to be understood as experts. Data was aggregated into a corpus and thematically relevant data was extracted, to assess patterns in metadiscourse.

Data was analysed in three ways. First, content analysis was used to generate an overall scheme of frequently-realised themes and subunits participants connected with their projected readers. Second, this data was re-unitised to enumerate specific kinds of readers. Third, transitivity analysis was used to examine the process types that participants attributed to themselves as writer, and also to text and reader. 


\section{Content Analysis}

Content analysis represents the thematic content realised in extensive textual data as a set of themes, broken down into sub-topic, as a set of realisation frequencies (Roberts, 2000). While the complete ideational content of a corpus may be coded, emergent coding schemes are more frequently used (Neuendorf, 2016). This tabulates frequencies only for themes and subtopics which have "a direct bearing on the question," producing smaller but more reliable frequency scores (Bazerman \& Prior, 2004, p. 19). The clause is used as a boundaried coding unit, as it is the smallest viable unit of meaning for generating frequency scores (Bryman, 2004). Syntactical units are felt to be "natural' relative to the grammar of the medium of the data" (Krippendorf 2012 , p. 105). The smallest contiguous range was taken to be between the single word and the clause (Krippendorf, 2013). "Metadiscourse is often realised by signals which can stretch to clause or sentence length" (Hyland, 2010, p. 126). In this study, clauses were coded for a single unit of meaning, with cross-clause and distal clauses counted separately, but n-gram dichotomous word-stem variables excluded (Hopkins \& King, 2010). Manifest content was included, but latent content excluded (Stemler, 2001).

The first content analysis focused on frequently-realised themes and subunits. This produced a coding frame comprising four themes, each with six subunits, as in Table 1.

Table 1

Emergent coding frame for participants' perceived readership

\begin{tabular}{ll}
\hline \multicolumn{1}{c}{ THEME } & \multicolumn{1}{c}{ SUBUNIT } \\
\hline improving the reader's comprehension & through language \\
& through research \\
& through data \\
& through visuals \\
& through structure \\
& through content \\
\hline improving the reader's experience & making it more enjoyable (unspecified) \\
& making it more popularly appealing \\
& including better data \\
& making it more visually interesting \\
& using better language \\
& tailoring it to reader identities \\
\hline making the reader believe your ideas & through persuasion (unspecified) \\
& through adding research \\
& through pleasant words \\
& through argumentation \\
& through excellent language proficiency \\
& through visuals \\
\hline
\end{tabular}


problems

confusing the reader

boring / demotivating the reader

placing burdens on the reader

poor language / grammar

poor structure

poor visuals

Thematic content was then reunitised, to construct a list of frequently-realised reader types (Krippendorf \& Bock, 2009). Clauses identifying readers through a noun or nominal group ("The ability to understand resources is one of the major skills that writers and communicators have to acquire", "I'm targeting individuals that are educated) were used to construct an emergent coding frame (Denzin \& Lincoln, 2000). The reunitised coding frame can be seen in Table 2 .

Table 2

Kinds of readers realised in reflection corpus

\begin{tabular}{ll}
\hline \multicolumn{1}{c}{ THEME } & \multicolumn{1}{c}{ SUBUNIT } \\
\hline Self as reader & \\
Instructor as reader & \\
Undefined reader & \\
Reader as target & \\
Reader as viewer & \\
Reader as language consumer & \\
Reader as content consumer & \\
Specialist readers & Educated \\
& $\begin{array}{l}\text { Politically informed } \\
\text { Defined by area of interest } \\
\end{array}$ \\
\end{tabular}

Content was coded by the lead researcher and a research assistant, each with more than 200 hours' experience. A concordancing program was used to identify word, collocation and colligation counts for specific terms within each subunit, in order to ensure accuracy and completeness (Baayen, 2008).

\section{Transitivity analysis}

People construe their experiences as processes unfolding in time. Processes, or verbs, convey the element of activity or change within the clause (Eggins, 2004). Because metadiscourse is a projection of the ideas of the writer, the process types selected to represent writer, text and reader reveal participant views about their own 
agency and identity (Halliday, 1994). Transitivity analysis focuses on how actors, participants and processes are construed within the clause (Martin, 2005). The "cornerstone of the semantic organization of experience" (Halliday, 1971, p. 19), processes are fundamental lexical items in human neurolinguistic processing (Druks, 2002; Vigliocco, Vinson, Druks, Barber \& Cappa, 2011). Process types encode a specific mental image of how reality works - its actions, actors, and circumstances - in the experience of the person realising them (Thompson, 2004). Processes are organised as a system network comprising six types and eleven categories (Halliday \& Matthiessen, 2004), as in Figure 1.

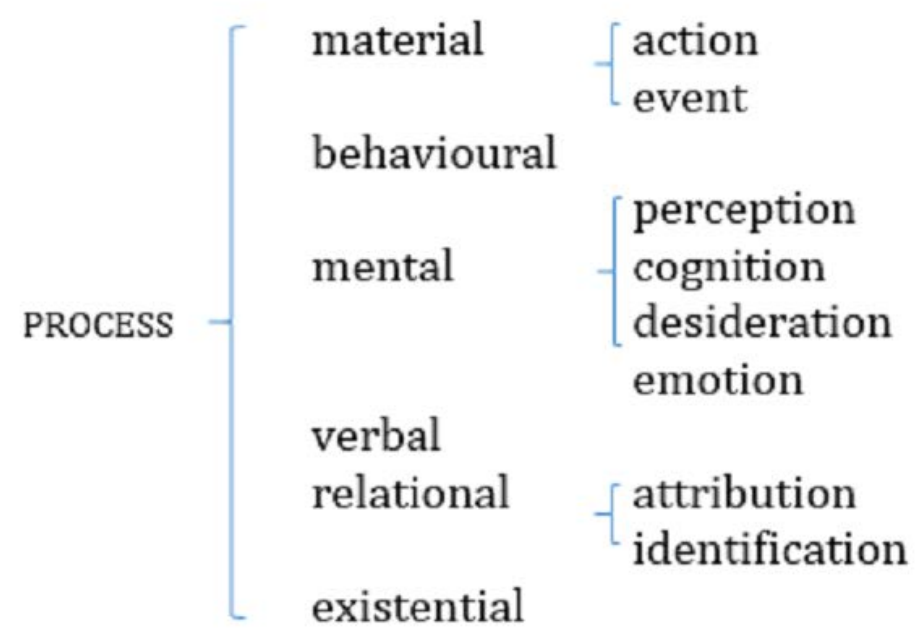

Figure 1. The process system network

Process types may be used as a coding scheme (Dong, Kleinsmann, \& Valkenburg 2009). Material processes construe events unfolding outside the self, either as an action transitively taking an object ("I researched the sources"), or as an event ("it is not the worst that could happen"). Mental processes construe Actors' experiences inside themselves ("I felt really disappointed"). Behavioural processes inhabit a medial position between these two, construing physiological events happening within the body of the Actor ("I always oversleep"). Relational processes construe the identification and characterisation of internal and external objects and events, through clausal extensions elaborating on the circumstances, usually through adverbial or prepositional phrases ("I collected data [extension:] about whether people believe in aliens or not"). Relational processes were not tabulated in this study, as most contained referential or ideational content, making it difficult to use them to understand how participants construe writers, texts and readers. Verbal processes mediate between mental and relational 
categories, and construe ways of saying ("today's session will help me improve my draft and clarify that"). Existential processes mediate between material and relational processes, construing simple being/not being. These realisations were too numerous and indefinite to illuminate participant views of readers, writers and texts, and thus were not tabulated.

Coding process types reveals patterns and regularities in a participant groups' understanding (Lavid \& Hita, 2002). Realisation frequencies were tabulated to detail how participants encoded the agency of readers, writers and texts. For this third method of analysis, clauses were again the unit of analysis, including clauses complexes organised by the same process (Martin, 2014). For example, the five clauses of this sentence are all extensions of the clause containing the verb "target": "(a) my targeted audience are people (b) who are more concerned (c) about studying the psychology of individual (d) when being exposed to visuals (e) such as business owners and marketing managers."

\section{Intercoder Reliability}

Inter-coder reliability was calculated for both content analyses, and the transitivity analysis (Freelon, 2016). The measure used was Cohen's $\kappa$ (free-margin and percent overall) (Lombard, Snyder-Duch \& Bracken, 2004).

\section{Data}

Individual reflections were aggregated into a corpus of 43075 words and 5881 clauses. Of these, 3998 clauses contained content relating to writers, texts and readers. Reliability values of 8.58 (f-m) and $8.40(\mathrm{p}-\mathrm{o})$ were robust, and not attributable to chance.

\section{Content analysis of frequently-realised themes and subunits}

Content sorted into four themes. The first comprised clauses focused on several methods participants felt would improve their projected readers' comprehension of their essay ("Interpreting these findings on a graphical representation is a helpful tool to explain to the audience the various findings"), as in Figure 2. 


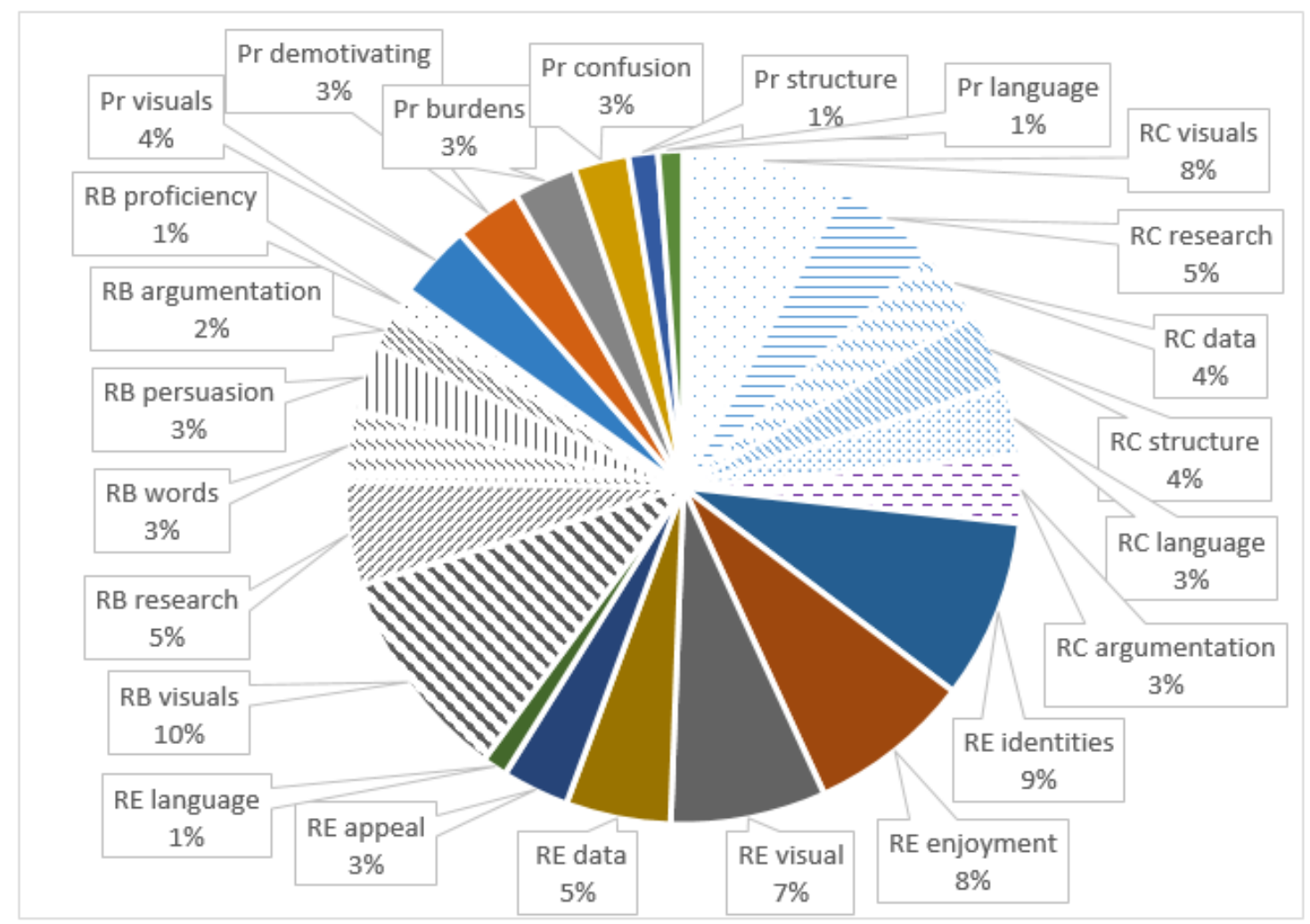

Figure 2. Content analysis themes and subunits

These clauses realised the concerned that readers understood the writers' referential content. The second comprised clauses focused on ways to improve readers' personal experience of reading their essay ("design aims to make the communicated data more appealing to the reader, allowing for the overall experience of reading to be more enjoyable and pleasant"). The third comprised clauses focused on methods participants felt would cause readers to believe their ideas. These clauses differed from those in the first two themes as they were directive, rather than invitational ("I now know that employing different sources in different topics is significant in making my writing more credible. The reader will then find the writing as being more authoritative and credible"). The fourth theme comprised a selection of problems participants anticipated they would encounter, as writers and within their texts. Subunits recurred across themes, including (a) visuals, (b) research, meaning reading research articles, government documents and so on, (c) data, meaning the numerical contents of graphs, tables and charts, (d) the organisation or structuring of the paper into sections such as the introduction, body paragraphs and conclusion and the use of thesis statement and topic sentences, and (e) language, comprising grammar, registerial choices, spelling and punctuation, though the latter two were not realised frequently. 


\section{Content analysis of reader types}

The reunitised content analysis yielded seven distinct kinds of readers projected by participants, plus an eighth omnibus category of specialist readers, as in Figure 3.

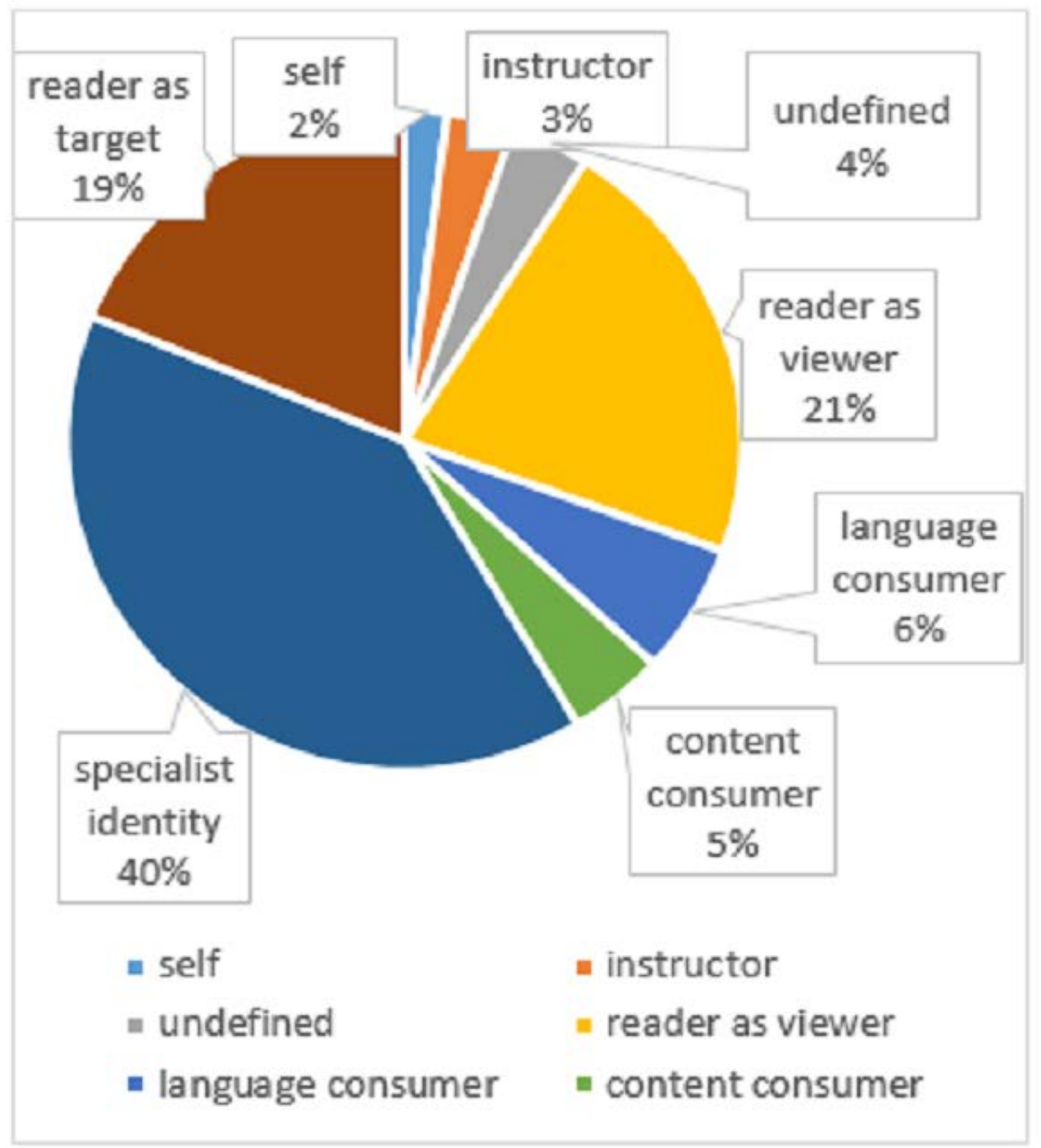

Figure 3. Re-unitised content frame: Kinds of readers

Of these reader types, projected specialist readers comprised the largest number at $40 \%$ ("My readers are in business", "my reader has to be in politics like me"). Readers understood as viewers were the next largest group at 21\% ("I can think of how to make it easier in steps for readers to see and understand the data and also retain faster", "when one sees, for example, a picture that is colorful and of high quality then the reader will feel a sense of attraction"). Finally, projected readers as targets comprised $19 \%$ of realisations ("my targeted audience are people who are more concerned about studying the psychology", "my target audience is consumers"). The instructor, who was understood by participants to be the only real reader, received only $3 \%$ or realisations. 


\section{Process analysis}

Of 3,998 clauses containing metadiscourse content, 2,110 contained process types that could be classified within the reduced schema, or were distal to such a clause. This produced different profiles for writer, text and reader as agents with very different characteristics, as in Figure 4.

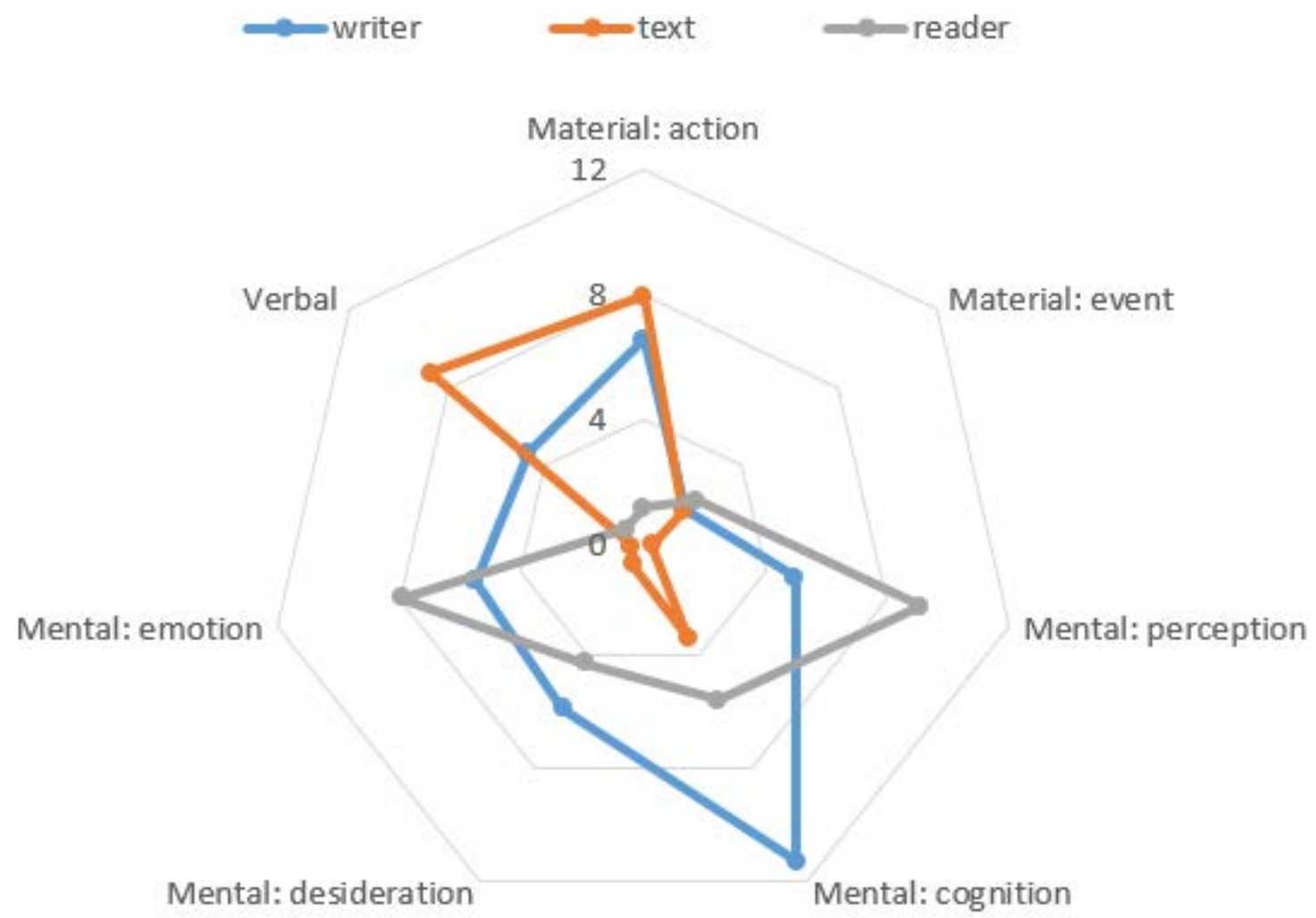

Figure 4. Process types realised by participants for writers, texts and readers

Writers were primarily characterised by cognition (understand, know) and material actions (develop, distinguish) ("a writer knows how to persuade," "the writer develops an emotional connection with the texts they read"). Texts were primarily characterised by saying (express, persuade) and material actions (make, target) ("this part expresses my mind", "my essay makes them think about the reality of this problem".) Readers were primarily characterised by mental perception (view, look) and emotions (enjoy, be interested) ("the reader gets a chance to see my point", "my audience is those who are interested in the human psyche in general. Who isn't my audience is those who are uneducated, uninterested.") 


\section{Inter-coder reliability}

Inter-coder reliability was calculated for both content coding frames, and also for the transitivity analysis, as in Table 3.

Table 3

Inter-coder reliability $(p-o, f-m)$

\begin{tabular}{lll}
\hline & P-O & F-M \\
\hline Content frame 1 & 0.828 & 0.810 \\
Content frame 2 & 0.834 & 0.823 \\
Transitivity & 0.815 & 0.806 \\
\hline
\end{tabular}

These values indicate robust reliability in the coding process, and are not attributable to chance.

\section{Discussion}

This study has limitations. It used a relatively small participant group in a single location, and analysed data from only 4 weeks, and the writing of a single essay. A larger participant cohort, and data from a greater time span within the first year would allow a more precise understanding of contemporary novice concepts of writers, readers and texts. Still, this study has demonstrated that novice writers have assertive, selfconfident concepts about their roles as writers. The statement, "[w]hen we write an essay, we don't write it as students we write it as writers" shows the awareness of taking on this role. Content analysis suggests that they understand this role as trying to interest and satisfy readers. They assume consonance between the writer's and the readers' role, projecting readers who occupy niches parallel to their writerly role, as shown in the example assuming psychologists write for people interested in psychology. They understand their reader as wanting to be satisfied, with reader satisfaction playing a more powerful part in defining the writer's role than any sense of the academic or expert role, or the academic qualities or content of a text.

Second, way these novices understand the writer-reader relationship resembles marketing concepts far more than traditional views of the expert. Thematic content from the first coding frame showed that participants were more concerned with providing readers with a good experience $(166=33.33 \%)$ than with improving reader comprehension $(133=26.71 \%)$. They were more concerned with making them believe the author's ideas $(124=24.90 \%)$, but not greatly concerned $(75=15.06 \%)$ with problems areas in their texts. For example: 
Nowadays, technology have provided individuals with a variety of tools to understand their resources in the simplest way possible; writers are obligated to explore their audience personalities and mentality to reach their communication goals. Identifying the audience is one of the magnificently relevant steps to the process, as it helps communicators to determine whether the understood resources used is properly related to their audience experiences, mentalities, and education.

Here, the writer understands his role as ensuring that his text coordinates well with his readers' daily experiences, including what they can find on the internet. In this example as in many other cases, these novices' sense of the writer's role resembles customer service.

Third, these novices privilege visual content in their understanding of how the writer should communicate, and what the reader does in order to understand the text. In the content analysis data, three of eight subunits understood visuals as assisting reader comprehension, constructing reader experiences, and making readers believe the author's views. Had these subunits been combined, they would have ccomprised nearly a third of all realisations. By comparison, participants downplayed data, research articles, and language, all of which would be more likely to challenge writers and readers, and make their relationship more complex and demanding.

These novices' understanding of writing conflates visual with textual elements, to the point that they almost fail to distinguish the two, for example:

Visual communication is a daily life routine which we go through in each second but we do not realize. I have learnt that each picture I see, I do analyse it in seconds and produce conclusions. This is what I can easily use to help my reader take my ideas

Here, the writer uses his previous visual experience to characterise himself as an average person, specifically applying this to how he reads and thinks, which he then applies to how he should write because this is how his readers also will read. Content analysis suggests that participants viewed visuals including graphs, charts, photographs, illustrations and infographics as more important than reading research articles, presenting data or using sophisticated language, in constituting effective authorship: "this deep, complex meaning can be achieved through clear visuals which 
appeal to the viewer." Analysis of the reunitised coding frame showed that these participants most frequently characterised their readers as viewers ("will see", "can see"). This indicates the profound degree to which contemporary novices are shaped by the media environment they live in, and by their own daily digital reading habits.

Fourth, the qualitative data analysed in this study revealed an implicit sensory disjuncture between writers and readers. At the same time, the prosaic reality that the instructor is the only actual and real reader seemed unimportant to them, suggesting that the impact of media saturation is a degree of fantasy in conceptualising the rhetorical situation. Transitivity analysis showed that these novices understood themselves as thinkers, but their readers as viewers. Participants represented themselves mainly as thinking, the most frequent activity in the corpus, but their readers mainly as perceiving (seeing or viewing), the second most frequent activity in the corpus. For example:

The writers have to express their thoughts and information in a professional way. Then it is much easier for the reader to see ending results and numbers based on the conducted survey rather than scattered numbers that will confuse the reader and decrease the readers motivation to learn more about a certain study conducted.

In sentence 1, the writer as actor realises thought. But in sentence 2, where the reader is the actor, the process enacted is seeing. Visuals are valorised as better than "scattered numbers". That is, this writer believes that placing numerical data into the text would require the reader to do too much work or work that was too difficult. In the tension between writing and readerly confusion, the demotivation of the reader is used as the proper way to make writerly decisions. This solution to the tension created by writerly expertise and readerly experience was seen in many cases. Transitivity analysis showed that texts were constructed as enacting verbal ("my essay claims") and materially-active ("My paper will make a dull topic interesting") processes. For example:

The text must refer to the pictures to engage the reader to look at the pictures and analyze. Tables, flowcharts and diagrams help a lot in your writing as it gives evidence and support to what is written. 
Here, the text is the actor and its activity is to engage, but the meaning of engage is extended in first in look, which indexes analyse, and only by implication, read. For these novices, then, the visual affordances of modern digital texts ha devalorised the role of words in conveying information.

Fifth, visuals are understood to be more powerful as agents of comprehension than text. To some degree, the integration of data into sentences, and the intellectual processes which formerly defined the process of reading - analysing and understanding - have been replaced by processes of seeing which require relatively little conceptual effort. These novices understand visuals as driving the readers' understanding than arguments constructed from words, or data in the form of numbers. For example:

Visuals have an enormous effect on how the reader views or receives the message behind the text or what is written. Every visual that is put in the text speaks for itself. For example, you can indicate and be sure of what the movie would be like because of its picture.

Here, visual elements of the text are rhetorically active, and the relationship between the words and the graphic is conceived as directly correspondent. The analogy with the movie poster is revealing. While not entirely incorrect, the recommendation to use visuals with an iconic character in expert writing is simplistic, compared to the relationship between, for example, an expert academic abstract and article. Many comments in the corpus understood the visual media as the primary referent in the readers' understanding, and this view governed their ideas of how to construct and relate to their readers:

I aim to achieve an overall meaning to the audience through vision. My visual communication incorporates the art of carefully selecting a suitable design and layout that is compatible with the delivered content, and the intended audience.

That is, while novice writers have understood the need to relate to the audience, they understand visuals as having primacy in achieving this goal. Thus they downplay or even fail to focus on content, the complexity of which must be mastered by the writer, in order to write at an expert level,. They choose to avoid burdening the reader with the work of reading and understanding complex content. Instead, they tend to conflate positive reader reception with a good understanding of content: 
with a picture that is colorful and of high quality then the reader will feel a sense of attraction, diverting full attention to the picture. If this picture is within a text then the reader will try to correlate its meaning to the text, therefore trying to find the message behind the picture.

This and many similar examples reveal the impacts on these novices, of growing up in a media-saturated context. This result highlights the need to teach multimodal rhetorical analysis, along with composition.

Sixth, the way these novices mix visual and textual elements should be used to retool our understanding of previous research on metadiscourse. These novices constructed a range of relationships with their projected readers, realising both invitational and directive dimensions of Hyland's cline. But they do so with visuals. In the comment, " $[\mathrm{w}]$ ithout the aid of visuals, such as diagrams, graphs, or pictures the text will not appeal to the reader as much as it would with one including them", the invitation lies in the process "appeal" which is done through visuals. In "graphs are specially good to use because they make it clear to the person what your idea is like, and exactly what you want to say", the directive is found in the verb "make". These novices' sense of metadiscourse is visual at least as much as it is textual. Another example clarifies this:

I had completely forgotten about flow charts, so perhaps now I can think of how to make it easier in steps for readers to see and understand the data and also retain faster.

Here, the writer's process ("think") is directed at ensuring better reader viewing, not better reading or thinking, and the writer understands seeing as closely analogous to comprehending ("see and understand"). In the word "retain", it is difficult to distinguish thinking and seeing.

Seventh, these novices viewed readers as an array of niche identities. Content from the reunitised frame showed that the largest theme by far collected specific reader identities as subunits, indicating that participants were highly aware of needing to shape their writing for specific readers. For example, in "[w]riters are obligated to explore their audience personalities and mentality to reach their communication goals", the novice focuses on the interiority or psychology of readers. In "I will be using 
sophisticated terminologies because my topic and my audience are both sophisticated and need to be clear to architects", the writer was an architecture student who understood herself to be writing for other architects. In "I am writing to a very sophisticated educated people who are interested in knowing the causes for sexual harassment especially in eastern countries, such as, K.S.A, Iran, and Egypt etc", the writer understands her audience as those engaged with a specific issue. In "I choose my audience depending on my topic" the writer is self-aware about this process of selecting specific sub-groups of readers.

These novices believe they should have a sophisticated and granular sense of demographic analysis of their intended readers. They wrote about reader attributes including personality, beliefs, education, interests, age and occupation. This perspective likely reflects their experiences living in a market-driven society. This view is relatively resistant to the EAP view of expert writers and readers. An expert academic writer would project academic readers with a professional grasp of methods and theories, able to follow complex content realised in advanced concepts and field-specific language. Despite more than forty hours of composition input, an academic concept of expert writing and reading is nearly absent from the corpus.

Finally, the strength of these novices' own beliefs, that they should write in ways that attract and satisfy readers, was more powerful than teacher talk and classroom input. That is, these novice writers set aside class input and teacher talk. In its place, these novices retain a customer service sense of their role and their proper relationship to their readers. All elements of EAP terminology and teacher talk take up a relatively small place in the corpus, and thus in the content and transitivity analyses. In particular, the following items had a small presence: (a) the organisation or structuring of the paper into sections such as the introduction, body paragraphs and conclusion and the use of thesis statement and topic sentences, and (b) elements of language and mechanics such as grammar, vocabulary and register, style, citation, spelling and punctuation. This result is consonant with the slight acknowledgement of the teacher as an audience or reader, and suggests that these novices' enter the EAP classroom with a robust preconception of their role as writer and of their proper relationship to their readers. This preconseption seems to interfere with EAP input, and may mean they fail to notice the value of composition course content, terminology and teacher talk. This 
has significance for EAP learning outcomes, as the elements these novices seemed to downplay connect fundamentally with the cognitive tasks involved in academic writing.

Overall, this study suggests that L2 freshers' sense of themselves as writers may not be best described by the word novice. A term such as 'conventional' may be more apt. The term 'novice' does capture their lack of understanding of the cognitive effort and attention to language required for expert writing. But it does not reflect their selfconfidence, or their conviction that they know who their audience is, and how they should reach them, and that pleasing them is more important than challenging them. That is, it does not capture the marketing character of their construction of their rhetorical style and task, their conflation of seeing and understanding, and their intellectual fusion of visually captivating an audience with expertly representing and exploring an issue. Advanced subject knowledge based in research-level reading, skilled reasoning and careful language, which are still required for a novice to become experienced, were notably under-realised in this corpus, despite the fact that they must have defined participants' classroom and conferencing experiences.

It seems that EAP teachers must find ways to challenge novices' ideas about writing and reading. The awareness of visual elements that these novices bring into the classroom could be sophisticated through integrating advanced multimodal analysis into composition courses (DePalma \& Alexander, 2015). Novices' concepts of expert writers and reader could be interrupted and interrogated with slower, more difficult and more authentic academic practices. This is a significant need, in a global media environment which routinely disdains and misrepresents expertise (Nieto-Galan, 2016). The field of marketing itself offers concepts which could be employed in EAP contexts for this purpose, distinguishing various kinds of worth - for example market worth as compared to real, equity and assessed worth. Marketing offers contemporary ethical frameworks based in relationships and objectives other than pleasing consumers (Eagle \& Dahl, 2015). These might be used to help students critically examine how they understand their identity as writers, their views of readers, and their understanding of the texts they write. 


\section{References}

Abdi, R. (2009). Projecting cultural identify through metadiscourse marking: A comparison and Persian and English research articles. Journal of Englishlanguage Teaching and Learning 52(212), 1-15.

Ädel, A. \& Mauranen, A. (2010). Metadiscourse: Diverse and divided perspectives. Nordic Journal of English Studies 9(2), 1-11. https://doi.org/10.35360/njes.215

Alexander, 0. (2012). Exploring teacher beliefs in teaching EAP at low proficiency levels. Journal of English for Academic Purposes 11(2), 99-111. https://doi.org/10.1016/j.jeap.2011.12.001

Al Falasi, H. (2007). Just say thanks-you: A study of compliment responses. The Linguistics Journal 2(1), 28-42.

Alshahrani, A. (2015). A cross-linguistic analysis of interactive metadiscourse devices employment in native English and Arab ESL academic writings. Theory and Practice in Language Studies 5(8), 1535-1542. https://doi.org/10.17507/tpls.0508.01

Bazerman, C. \& Prior, P. (2004). What writing does and how it does it: An introduction to analysing texts and textual practices. Mahwah NJ, Erlbaum. https://doi.org/10.4324/9781410609526

Baayen, R. (2008). Analyzing linguistic data: A practical introduction to statistics. Cambridge, Cambridge University Press. https://doi.org/10.1017/CB09780511801686

Biber, B., \& Gray, B. (2010). Challenging stereotypes about academic writing: Complexity, elaboration and explicitness. Journal of English for Academic Purposes 9(1), 2-20. https://doi.org/10.1016/i.jeap.2010.01.001

Block, D. (1998). Exploring interpretations of questionnaire items. System 26(3), 40325. https://doi.org/10.1016/S0346-251X(98)00022-0

Bryman, A. (2004). Social research methods. Oxford University Press, Oxford.

Carley, K. (1990). Content analysis. In Asher, R. (Ed.) The encyclopedia of language and linguistics. Edinburgh, Pergamom Press, 725-730.

Chen, S., Cheung, F., Bond, M. \& Leung, J. (2005). Decomposing the construct of ambivalence over emotional expression in a Chinese cultural context. European Journal of Personality 19(3), 185-204.

Cheng, X. (2000). Asian students' reticence revisited. System 28(3), 435-446. https://doi.org/10.1016/S0346-251X(00)00015-4

Connor, U. Nagelhout, E. \& Rozycki, W. (2008). Contrastive rhetoric: Reaching to intercultural rhetoric, Vol. 169. Amsterdam and Philadelphia PA, John Benjamins. https://doi.org/10.1075/pbns.169

Crystal, D. (2006). Language and the internet. Cambridge, Cambridge University Press. https://doi.org/10.1017/CB09780511487002 
Denzin, N. \& Lincoln, Y. (2000). Handbook of qualitative research. Thousand Oaks, Sage.

DePalma, M-J. \& Alexander, K. P. (2015). A bag full of snakes: Negotiating the challenges of multimodal composition. Computers and Composition 37, 182-200. https://doi.org/10.1016/i.compcom.2015.06.008

Doiz, A., Lasagabaster, D., \& Sierra, J. (2011). Internationalisation, multilingualism and English-medium instruction. World Englishes 30(3), 345-359. https://doi.org/10.1111/j.1467-971X.2011.01718.x

Dong, A., Kleinsmann, M, \& Valkenburg, R. (2009). Affect-in-cognition through the language of appraisals. Design Studies 30(2), 138-153. https://doi.org/10.1016/i.destud.2008.12.003

Druks, J. (2002). Verbs and nouns - A review of the literature. Journal of Neurolinguistics 15(3), 289-315. https://doi.org/10.1016/S0911-6044(01)00029-X

Eagle, L. \& Dahl, S. (2015). Marketing ethics \& society. Sage, Thousand Oaks. https://doi.org/10.4135/9781473920415

Eggins, S. (2004). An introduction to systemic functional linguistics, London, Continuum.

Fitze, M. (2006). Discourse and participation in ESL face-to-face and written electronic conferences. Language Learning and Technology 10(1), 67-87.

Freelon, D. (2010) ReCal: Intercoder reliability calculation as a web service. International Journal of Internet Science 5(1), 20-33.

Gilquin, G. \& Paquot, M., (2008). Too chatty: Learner academic writing and register variation. English Text Construction 1(1), 41-61. https://doi.org/10.1075/etc.1.1.05gil

Graddol, D. (2006). English Next. British Council, The English Company UK, Retrieved from https://www.teachingenglish.org.uk/sites/teacheng/files/pub english next.pdf

Halliday, M. A. K. (1994). An introduction to functional grammar. London and New York: Arnold.

Halliday, M.A.K. \& Matthiessen, C.M.I.M. (2004). An introduction to functional grammar. London, Hodder Education.

Hopkins, D. \& King, G. (2010). A method of automated nonparametric content analysis for social science. American Journal of Political Science 54(1), 229-247. https://doi.org/10.1111/j.1540-5907.2009.00428.x

Hyland, K. (2002). Directives: Argument and engagement in academic writing. Applied linguistics 23(2), 215-239. https://doi.org/10.1093/applin/23.2.215

Hyland, K. (2004). Disciplinary interactions: Metadiscourse in L2 postgraduate writing. Journal of second language writing 13(2), 133-151. https://doi.org/10.1016/j.jslw.2004.02.001

Hyland, K. (2005). Metadiscourse. London, John Wiley \& Sons. 
Hyland, K. (2010). Metadiscourse: Mapping interactions in academic writing. Nordic Journal of English Studies 9(2), 125-143. https://doi.org/10.35360/njes.220

Hyland, K., \& Tse, P. (2004). Metadiscourse in academic writing: A reappraisal. Applied linguistics 25(2), 156-177. https://doi.org/10.1093/applin/25.2.156

Krippendorf, K. (2013). Content analysis: An introduction to its methodology, London, Sage.

Krippendorf, K. \& Bock, M. (2009). The content analysis reader. London, Sage.

Lavid, J. \& Hita, J. (2002). Nuclear transitivity in English and Spanish: A contrastive functional study. Languages in Contrast 4(1), 75-103.

https://doi.org/10.1075/lic.4.1.05lav

Lombard, M., Snyder-Duch, J. \& Bracken, C. (2004). Practical resources for assessing and reporting inter-coder reliability in content analysis research projects. Retrieved from Retrieved from

https://www.researchgate.net/profile/Cheryl Bracken/publication/242785900 Practical Resources for Assessing and Reporting Intercoder Reliability in Con tent Analysis Research Projects/links/0deec52e14791a0d6f000000.pdf

Mangan, S. (2008). Mediating discourse online. Amsterdam, John Benjamins.

Martin, J. (2014). Evolving systemic functional linguistics: beyond the clause. Functional Linguistics 1(1), 3-24.

Martin, J., \& Rose, D. (2003). Working with discourse. London. Continuum.

Megahed, I. (Ed.) (2016). AUC Factbook 2015-2016. Egypt, American University in Cairo.

Meunier, F \& Granger, S. (Eds.) (2008). Phraseology in Foreign Language Learning and Teaching. Amsterdam and Philadelphia, John Benjamins.

https://doi.org/10.1075/z.138

Mur-Dueñas, P. (2011). An intercultural analysis of metadiscourse features in research articles written in Spanish and English. Journal of Pragmatics 43(12), 3068-3079. https://doi.org/10.1016/j.pragma.2011.05.002

Negretti, R., \& Kuteeva, M. (2011). Fostering metacognitive genre awareness in L2 academic reading and writing: A case study of pre-service English teachers. Journal of Second Language Writing 20(2), 95-110. https://doi.org/10.1016/j.jslw.2011.02.002

Neuendorf, K. (2016). The content analysis guidebook. London, Sage. https://doi.org/10.1002/9781118541555.wbiepc065

Neumann, W. (2013). Social research methods: Qualitative and quantitative approaches. London, Pearson Education.

Nieto-Galan, A. (2016). Science in the public sphere: A history of lay knowledge and expertise. Routledge, UK. 
Pérez-Llantada, C. (2010). The discourse functions of metadiscourse in published academic writing: Issues of culture and language. Nordic Journal of English Studies 9(2), 41-68. https://doi.org/10.35360/njes.217

Ramanathan, V. \& Kaplan, R. (2000). Genres, authors, discourse communities: theory and application for L1 and L2 writing instructors. Journal of Second Language Writing 9(2), 171-191. https://doi.org/10.1016/S1060-3743(00)00021-7

Roberts, C. (2000). A conceptual framework for quantitative textual analysis. Quantity and Quality 34(3), 259-274. https://doi.org/10.1023/A:1004780007748

Roberts, C. (Ed.) (1997). Text analysis for the social sciences: Methods for drawing statistical inferences from texts and transcripts. Mahwah, NJ, Erlbaum.

Søndergaard, M. (2012). Hofstede's consequences: A study of reviews, citations and replications. Organizational Studies 15(3), 447-456.

Stemler, S. (2001). An overview of content analysis. Practical assessment, research and evaluation 7(17), 137-146.

Sultan, A. H. (2011). A contrastive study of metadiscourse in English and Arabic linguistics research articles. Acta Linguistica 5(1), 28.

Thompson, G. (2004). Introducing functional grammar. London and New York, Oxford University Press.

Unsworth, L. (Ed.) (2005) Researching language in schools and communities: Functional linguistic perspectives. London, Cassell, 275-302.

Vande Kopple, W. (2012). The importance of studying metadiscourse. Applied Research in English 1(2), 37-44.

Vigliocco, G., Vinson, D., Druks, J., Barber, H. \& Cappa, S. (2011). Nouns and verbs in the brain: A review of behavioural, electrophysiological, neurophysiological and imaging studies. Neuroscience and Biobehavioral Reviews 35, 407-426.

https://doi.org/10.1016/j.neubiorev.2010.04.007

Wei, Y. \& Lei, L. (2011). Lexical bundles in the academic writing of advanced Chinese learners. RELC: A Journal of Language Teaching and Research 42(2), 155-166. https://doi.org/10.1177/0033688211407295

Yao, X. (2000). An introduction to Confucianism. Cambridge, Cambridge University Press. https://doi.org/10.1017/CB09780511800887

Zlatev, J., Racine, T. P., Sinha, C., \& Itkonen, E. (Eds.) (2008). The shared mind:

Perspectives on intersubjectivity. Amsterdam, John Benjamins.

https://doi.org/10.1075/celcr.12 